\title{
ENSAIOS MECÂNICOS EM AGLOMERADOS AUTORREDUTORES DE CONCENTRADO DE NÍQUEL*
}

Ramiro da Conceição do Nascimento Júmior Horst Guenter Feldhagen ${ }^{2}$

Rafael Piumatti de Oliveira ${ }^{3}$ João Batista Conti de Souza 4

Claudio Patrocinio Junior ${ }^{5}$ Antonio Clareti Pereira ${ }^{6}$

\section{Resumo}

O uso de minérios lateríticos na metalurgia extrativa do níquel tem demandado investimentos em pesquisa e acordos de cooperação técnica para o desenvolvimento de tecnologias mais econômicas e produtivas. Devido às características de difícil processamento do minério e pelo decréscimo da sua quantidade e qualidade, ressalta-se a necessidade de se determinar técnicas efetivas de concentração, que possibilitem o aproveitamento de minérios marginais finos. Estabelece-se então, dentro de uma rota de processamento proposta, a estratégia de se produzir aglomerados (pelotas e/ou briquetes) a partir de concentrado de níquel. Além da fabricação dos aglomerados, faz-se necessária a sua caracterização em uma série de ensaios, para servir de base para a certificação desse produto e sua aplicação em processos de obtenção de ferro níquel ou gusa enriquecido com níquel. Um dos ensaios realizados envolve a caracterização física desses aglomerados. $O$ ensaio foi realizado em máquina universal de ensaios, observando-se a resistência à compressão de amostras de aglomerados que passaram por diferentes tipos de rotas de processamento, e de diferentes etapas do processo de pelotização. Os resultados mostram que os aglomerados submetidos ao ensaio possuem resistência à compressão de pelotas verdes e secas de minério de ferro, conforme o esperado.

Palavras-chave: Níquel; Aglomeração; Caracterização; Ensaios.

\section{MECHANICAL TESTS FOR SELF-REDUCING AGGLOMERATES OF NICKEL CONCENTRATE}

\section{Abstract}

The utilization of lateritic ores in extractive metallurgy of nickel has required investments in research and technical cooperation agreements to development of more economic and productive technologies. Due the characteristics of difficult processing of the ore, and the decrease in it's quantity and quality, points up the importance of effective concentration techniques that aim at the use of fine fractions of marginal ores. Then it settles the strategy to produce agglomerates (pellets and / or briquettes) from nickel concentrates within a proposal of processing routes. In addition to manufacturing agglomerates, it is necessary to characterize such agglomerates, in series of tests, to be base on the certification of this product and application in processes to obtaining nickel-ferro-alloys or nickel pig iron enriched with nickel. One of the performed assays involves the physical characterization of such agglomerates. The test was made in universal testing machine, observing the compression strength of samples that passed through different processing routes, and different stages of the pelletizing process. The results show that the agglomerates compression resistance was close to the value known to iron ore dried pellets, as expected.

Keywords: Nickel; Agglomeration; Characterization; Tests.

1 Doutor Eng. Metalúrgica, Eng. Metalurgista, Servidor Público/Professor Pesquisador, PROPEMM - Programa de Pós Graduação em Engenharia Metalúrgica e de Materiais, IFES - Instituto Federal de Educação, Ciência e Tecnologia do Espírito Santo, Vitória, ES, Brasil.

2 Doutor em Engenharia/Engenheiro Metalurgista, Servidor Público/Coordenador, Coordenadoria de Engenharia Metalúrgica, IFES, Vitória, ES, Brasil.

3 Eng. Metalurgista, Mestrando Eng. Met. e de Mat., Bolsista/Pesquisador, PROPEMM, IFES, Vitória,ES, Brasil.

4 Eng. Metalurgista e de Materiais - Aglomeração e Tratamento de Minérios, Professor Pesquisador, Coordenadoria de Engenharia Metalúrgica, IFES, Vitória, ES, Brasil.

5 Técnico em Mecânica, Graduando em Eng. de Controle e Automação, Servidor Público/Técnico, Coordenadoria de Mecânica, IFES, Vitória, ES, Brasil.

6 Mestre em Eng. de Materiais/Eng. Químico, Bolsista/Desenvolvimento Tec. Industrial, CNPq, Ministério da Ciência, Tecnologia e Inovação, Brasília, DF, Brasil. 


\section{INTRODUÇÃO}

As ferro ligas e gusa enriquecidos com níquel obtidos pelo processamento pirometalúrgico dos minérios lateríticos de baixo teor, tem sido estratégia adotada para suprir a demanda de níquel, principalmente na produção dos aços inoxidáveis. No caso dos austeníticos, têm-se o exemplo de que a matéria-prima representa aproximadamente $70 \%$ do custo total [1].

De acordo com Crundwell et al. [2] (2011, p.1, tradução), "Embora aproximadamente $70 \%$ das reservas minerais sejam encontradas em minérios lateríticos, somente $40 \%$ da produção do níquel se dá a partir das lateritas". Essa informação mostra que também há um amplo espaço de crescimento na exploração do minério laterítico frente aos minérios sulfetados que estão se exaurindo, apesar do baixo teor.

A ausência de uma etapa de "upgrade" do minério laterítico é uma dificuldade encontrada nos processos da metalurgia extrativa do níquel. Isso resulta em investimentos de alto custo de capital e operacional, nas plantas que processam enormes quantidades de matéria-prima, na extração do metal [3].

A rota pirometalúrgica de processamento das lateritas requer uma matéria-prima com granulometria adequada para alimentação dos fornos de redução. O intuito é de não prejudicar a permeabilidade do leito. Com isso, finos gerados no tratamento desses minérios acabam por se transformar em rejeito causando problemas ambientais.

Portanto, para tornar apto o uso desse co-produto, como carga nos fornos de redução dos produtores de ferro níquel ou gusa enriquecido com níquel, é requisitado um processo economicamente e tecnicamente viável. Além de que perpasse pela produção de um intermediário que para ser aplicado aos fornos específicos é necessária uma etapa de aglomeração.

A fabricação de aglomerados (pelotas e/ou briquetes) de minérios de níquel, à quente ou à frio, foi pouco estudada até o momento pelos produtores de níquel, incluindo a Vale SA. Os poucos estudos realizados com aglomeração à quente apresentaram resultados insatisfatórios no que tange à resistência mecânica, com exceção da rota cura à frio, ao ar. Mas dos estudos em andamento, torna-se importante caracterizar os aglomerados de concentrados, tendo como base os estudos já realizados com o minério. Vale ressaltar que a literatura apresenta dados de resistência à compressão de pelotas de minério de ferro, com influência dos aglomerantes comumente aplicados [4].

\section{MATERIAIS E MÉTODOS}

\subsection{Equipamentos utilizados}

- Balança Analítica BEL equipamentos LTDA - IFES, Campus Vitória;

- Estufa Quimis - IFES, Campus Vitória;

- Forno Tubular - IFES, Campus Vitória;

- Máquina de Ensaios Universal EMIC DL 10000 - IFES, Campus Vitória;

- Disco de Pelotização (Engendrar Engenheiros e Associados Ltda.) - IFES, Campus Vitória.

\subsection{Aglomeração do concentrado}

A produção dos aglomerados de concentrado foi feita seguindo as etapas comuns de: preparação e caracterização da matéria-prima e aditivos; mistura e 
homogeneização; pelotamento; classificação das pelotas; caracterização das pelotas. Foi realizada a aglomeração do concentrado de níquel em disco de pelotização (Engendrar Engenheiros e Associados Ltda.), em escala piloto, com elaboração de diferentes tipos de pelotas e rotas de processamento.

\subsection{Ensaio de resistência à compressão de aglomerados do concentrado}

Poucos ensaios de resistência à compressão de aglomerados de níquel foram realizados até o momento. Foram utilizados como base os ensaios regidos pela norma ISO para pelotas de minérios de ferro [5]. Vale ressaltar que seguindo essa norma foram estabelecidos os seguintes parâmetros de ensaio, conforme a tabela 1.

Tabela 1. Parâmetros e configurações escolhidos para o ensaio de resistência à compressão

\begin{tabular}{c|c}
\hline Parâmetros & Configurações \\
\hline Célula de carga & Aprox. 100 daN \\
Força Máxima & Aprox. 96 daN \\
Velocidade & Aprox. $1,67.10^{-4} \mathrm{~m} / \mathrm{s}$ \\
\hline
\end{tabular}

Inicialmente fez-se um teste para verificar o atendimento do critério de parada por ruptura em deformação. Esse critério foi estabelecido no script de programação do equipamento, através de configuração do ensaio predefinido (parada em $50 \%$ da deformação), conforme a granulometria da pelota submetida. O segundo teste foi realizado com uma pelota seca para checar o critério de parada por queda da carga em 50\%, conforme norma ISO 4700:2010.

Os ensaios foram realizados nas pelotas oriundas das diferentes rotas e estágios do processamento, conforme mostra a Tabela 2. Optou-se também por realizar ensaios com bem menos amostras que o proposto pela norma para minérios de ferro. Para esses resultados de resistência à compressão, foi feito um simples tratamento estatístico, visto o número reduzido de amostras.

Tabela 2. Matriz dos ensaios de resistência à compressão em função das rotas de experimentos

\begin{tabular}{c|l}
\hline Amostra/Ensaio & Rota de Aglomeração \\
\hline $1-2-3$ & Quente 1 (Pelota seca) \\
$4-5-6$ & Fria 2 (Cura ao ar) \\
$7-8-9$ & Fria 2 (Cura a $\left.70^{\circ} \mathrm{C}\right)$ \\
$10-11-12$ & Fria 2 (Cura a $\left.140^{\circ} \mathrm{C}\right)$ \\
$13-14-15$ & Fria 2 (Cura a $\left.160^{\circ} \mathrm{C}\right)$ \\
$16-17-18$ & Fria 2 (Cura a $\left.180^{\circ} \mathrm{C}\right)$ \\
\hline
\end{tabular}

\section{RESULTADOS E DISCUSSÃO}

\subsection{Aglomeração do concentrado}

$\mathrm{Na}$ etapa de preparação e caracterização da matéria-prima e aditivos, foi feita a secagem do concentrado de níquel e desagregação das partículas, pois foi constatado por diferentes técnicas, que a granulometria desse material é bem fina e consequentemente sua superfície específica é alta. Notou-se também que a matéria- 
prima principal tem como característica ser higroscópica, e assim, foi armazenada em local condicionado. Os aditivos foram também preparados e caracterizados. Um balanço de massa foi estabelecido para cada uma das duas rotas de processamento. O que totaliza dois traços de mistura para pelotamento, com escolha de aglomerante e outros aditivos, conforme os requisitos técnicos conhecidos para cada um dos casos e função a que se destina o produto. A homogeneização das misturas foi feita manualmente em metodologia de bancada, sem utilização de equipamentos misturadores e a aspersão de água foi feita com auxílio de borrifador. A figura 1 apresenta essa etapa.

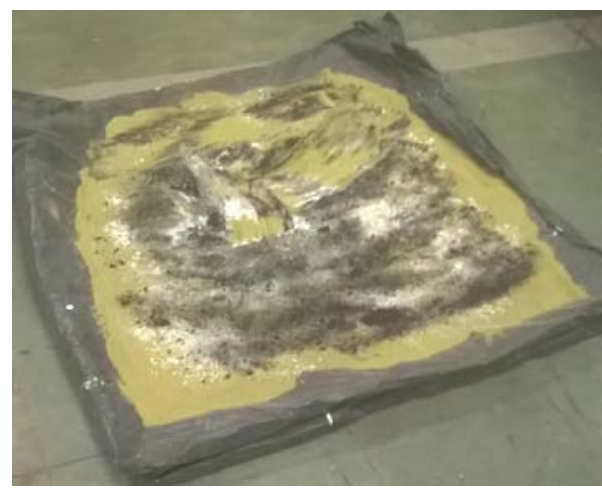

Figura 1. Mistura e homogeneização

No pelotamento, seguiu-se o conhecimento adquirido anteriormente pelos pesquisadores com o concentrado de níquel. As pelotas produzidas foram selecionadas pela granulometria e para o caso das pelotas da rota à frio foi realizado um teste de queda (resiliência).

A figura 2 apresenta as amostras de pelotas prontas para realização do processo de cura.

Figura 2. Pelotas antes da cura

As pelotas foram submetidas de acordo com a matriz de experimentos préestabelecida. E então armazenadas para posterior ensaio de compressão.

\subsection{Ensaio de resistência à compressão}

Os testes iniciais para avaliação do critério de parada da máquina de ensaios mostraram-se condizentes, pois o ensaio foi interrompido na compressão da pelota, ao atingir o valor de $50 \%$ da carga máxima aplicada ou $50 \%$ da deformação.

Para as amostras seguintes, que foram ensaiadas, já se pressupunham resultados de resistência à compressão inferior a 100 daN, por não se tratarem de aglomerados de boa performance. Esse resultado esperado tem como base os primeiros resultados de resistência das pelotas, observações da superfície e dos dados 
obtidos na literatura para as mesmas rotas em aglomerados de minério de ferro. Portanto a célula de carga escolhida foi a de $100 \mathrm{daN}$.

A tabela 3 mostra os resultados de resistência à compressão das diferentes rotas de processamento de pelotas.

Tabela 3. Resultados de resistência à compressão de acordo com o tipo de pelota (daN/pelota)

\begin{tabular}{l|cccc}
\hline Rota de Aglomeração & Mín & Máx & Média & Desv. Pad. \\
\hline Quente 1 (Pelota seca) & 0,25 & 1,00 & 0,72 & 0,41 \\
Fria 2 (Cura ao ar) & - & - & 78,33 & - \\
Fria 2 (Cura a $70^{\circ} \mathrm{C}$ ) & 3,31 & 4,98 & 3,93 & 0,92 \\
Fria 2 (Cura a $\left.140^{\circ} \mathrm{C}\right)$ & 2,82 & 3,51 & 3,27 & 0,39 \\
Fria 2 (Cura a $\left.160^{\circ} \mathrm{C}\right)$ & 2,23 & 5,43 & 4,06 & 1,65 \\
Fria 2 (Cura a $180^{\circ} \mathrm{C}$ ) & 0,48 & 0,61 & 0,56 & 0,07 \\
\hline
\end{tabular}

Obs.: 0 resultado de resistência à compressão da pelota da rota fria 2 (cura ao ar) foi obtido pelo ensaio de uma pelota.

Os resultados para a pelota de cura a $180^{\circ} \mathrm{C}$ e da pelota seca rota a quente apresentaram valores de resistência insatisfatórios. O que se interpreta desse resultado é que o aglomerado não está resistindo à velocidade e o modo de secagem. Assim, são geradas trincas, que enfraquecem a estrutura. As pelotas de cura a 70,140 e $160{ }^{\circ} \mathrm{C}$ apresentaram valores de resistência próximos aos de pelotas secas da rota de aglomeração a quente de minérios de ferro ( 3 a 5 daN/pelota) [6]. A tendência observada é que com o aumento da temperatura a resistência à compressão da pelota diminua, com exceção da cura à $160^{\circ} \mathrm{C}$, que teve um processamento especial em atmosfera gasosa e com isso resistiu melhor aos fenômenos de secagem.

Outros resultados obtidos de pelotas feitas com o concentrado de (MHP) podem ser comparados com os das pelotas de minério de níquel. A tabela 4 mostra os valores de resistência à compressão das pelotas de minério de níquel, obtidos em estudos feitos anteriormente por um dos pesquisadores.

Tabela 4. Resistência à compressão de pelotas de minério de níquel aglomeradas a quente e a frio (daN/pelota)

\begin{tabular}{l|cccc|cccc}
\hline \multirow{2}{*}{ Parâmetros } & \multicolumn{4}{|c|}{ Aglomerados a quente } & \multicolumn{4}{c}{ Aglomerados a frio } \\
\cline { 2 - 8 } & Ref & CC & CD & FM & Ref & CC & CD & FM \\
\hline RC & 145 & 121 & 110 & 134 & 168 & 132 & 120 & 138 \\
Desv. & 61 & 70 & 70 & 63 & 64 & 78 & 76 & 59 \\
\hline
\end{tabular}

Observações e legendas: RC - Resistência à compressão (valores aproximados em daN/pelota); Desv. = Desvio padrão dos resultados de resistência à compressão; Ref - pelota de referência;

CC - pelotas com carvão; CD - pelotas c/ calcário dolomítico; FM - pelotas com finos de mármore.

As pelotas de concentrado (MHP) apresentaram resultados de resistência à compressão abaixo dos valores comumente encontrados para pelotas de minério de ferro e níquel. O resultado que mais se aproxima é o da pelota da rota a frio (cura ao ar). Fica evidente a existência de fatores que podem estar contribuindo para a fragilidade dos aglomerados. Entre eles estão a saída de voláteis da matéria-prima 
no processo, o tipo de tratamento térmico, os aglomerantes e a composição da mistura utilizada.

\section{CONCLUSÃO}

O padrão aplicado para caracterização física de resistência à compressão de aglomerados de minério de ferro foi muito bem adaptado para aglomerados de concentrado de níquel. Com isso, o ensaio de resistência à compressão mostrou-se suficiente para gerar dados concretos aos aglomerados de concentrado de níquel. Além disso, a complementação dos resultados do ensaio de resistência à compressão com os dados da literatura, possibilita estudos de melhoria dos aglomerados produzidos, durante à etapa de pesquisa, e que servirá também para futura caracterização dos aglomerados.

Os valores de resistência à compressão apresentaram-se inferiores aos de aglomerados de minérios de níquel e alguns deles eram característicos de pelotas secas de minério de ferro. Somente o aglomerado de cura ao ar que apresentou resultado próximo ao de minério de níquel.

\section{Agradecimentos}

À Capes pelo auxílio através das bolsas de mestrado para dedicação exclusiva.

Ao CNPq, pelo apoio aos institutos e universidades federais nos projetos de pesquisas aplicadas em parcerias com as empresas e pelo auxílio no projeto: Produção de concentrado de níquel por pelotização redutora, Edital 94-2013;

Ao IFES - Instituto Federal de Educação, Ciência e Tecnologia do Espírito Santo, pelas instalações, espaços físicos e equipamentos utilizados nesse trabalho.

Ao ITV - Instituto Tecnológico Vale, pela parceria com o IFES no projeto, fornecendo material para os testes e apoio técnico nas realizações de ensaios.

À Vale - Diretoria de Pelotização, por todo apoio técnico (visita às instalações, compartilhamento do conhecimento e pelo fornecimento de aditivos e aglomerantes, para produção das pelotas).

\section{REFERÊNCIAS}

1 Rao M, Li G, Jiang T, Luo J, Zhang Y, Fan X. Carbothermic reduction of nickeliferous laterite ores for nickel pig iron production in china: a review. Journal Of The Minerals Metals \& Materials Society 2013; Vol.65(11); 1573-1583.

2 Crundwell F, Moats M, Ramachandran V, Robinson T, Davenport W. G. Extractive Metallurgy of Nickel, Cobalt and Platinum Group Metals. 1a. ed. Great Britain: Elsevier; 2011.

3 King M. G. Nickel Laterite Technology - Finally a new dawn? Journal Of The Minerals Metals \& Materials Society 2005; Vol.57(7); 35-39.

4 Meyer, K. Pelletizing of iron ores. 1. ed. Düsseldorf, Alemanha: Springer-Verlag. Berlin, 1980. 302pp.

5 International Organization for Standardization. ISO 4700:2010. Iron ore pellets for blast furnace and direct reduction feedstocks - Determination of the crushing strength.

6 Luz, A. B. da; Sampaio, J. A.; França, S. C. A. Tratamentos de minérios $-5^{\text {a }}$ Ed. Rio de Janeiro: CETEM/MCT, 2010. 